\title{
Predictors of Low Colorectal Cancer Screening in an Urban Academic Family Practice
}

\author{
Shaelyn Culleton ${ }^{1,2}$, Morgan Slater ${ }^{2}$, Aisha Lofters ${ }^{1,3}$ \\ ${ }^{1}$ Department of Family \& Community Medicine, University of Toronto, Toronto, Canada \\ ${ }^{2}$ Department of Family \& Community Medicine, St. Michael's Hospital, Toronto, Canada \\ ${ }^{3}$ Centre for Research on Inner City Health, The Keenan Research Centre in the Li Ka Shing, Knowledge Institute \\ of St. Michael's Hospital, Toronto, Canada \\ Email: Aisha.Lofters@utoronto.ca
}

Received 19 April 2014; revised 22 May 2014; accepted 5 June 2014

Copyright (C) 2014 by authors and Scientific Research Publishing Inc.

This work is licensed under the Creative Commons Attribution International License (CC BY).

http://creativecommons.org/licenses/by/4.0/

c) (i) Open Access

\begin{abstract}
Purpose: The primary objective was to describe the specific socio-demographic variables that are associated with colorectal cancer (CRC) under-screening in an urban, inner city population. The secondary objective was to determine the overall proportion of eligible patients who are not appropriately screened. Methods: A retrospective chart review of patients eligible for average-risk CRC screening as per Ontario's ColonCancerCheck program guidelines was conducted at an academic, inner city family health practice associated with St. Michael's Hospital in Toronto, Ontario. Simple measures of association, including t-tests and chi-square tests, were used to determine the relationships between screening and demographic characteristics. Based on a type I error rate of 0.05 and an appropriate sample size, the calculated power for this study was 0.82 . Results: A total of 200 patients were randomly selected; $54 \%$ were male; the majority were non-immigrants (77.5\%) and were employed or retired (76.5\%). Fifty-five percent of screened patients were up to date as per guidelines; $29.5 \%$ and $31 \%$ were up to date with a fecal occult blood test or a colonoscopy respectively. Individuals with psychiatric illness $(p=0.0005)$, with no history of prior cancer screening for other cancers $(p=0.0001)$, on disability or unemployed $(p=0.0010)$, or who were younger $(p=0.0062)$ were significantly less likely to undergo CRC screening. Conclusion: Colorectal cancer screening rates at this academic, urban family practice were very similar to province wide screening rates. Future studies should focus on group specific interventions to increase CRC screening uptake in low CRC screened populations.
\end{abstract}

\section{Keywords}

Colorectal Neoplasms, Early Detection of Cancer, Vulnerable Population, Secondary Prevention

How to cite this paper: Culleton, S., Slater, M. and Lofters, A. (2014) Predictors of Low Colorectal Cancer Screening in an Urban Academic Family Practice. Open Journal of Preventive Medicine, 4, 438-445.

http://dx.doi.org/10.4236/ojpm.2014.46051 


\section{Introduction}

Colorectal cancer (CRC) is currently the third most prevalent cancer and second most common cause of cancer mortality among Canadians, with an estimated 23,800 new cases and 9200 projected deaths expected for 2013 [1]. Despite its high prevalence, incidence and mortality rates have declined significantly since 2003 (0.8\% and 2.6\% annually respectively) [1]. Though much of this appreciable decline in mortality has been due to advances in treatment modalities such as chemotherapy, CRC screening programs are also thought to be partially responsible for the favourable trend [1].

In April 2008, Cancer Care Ontario (CCO) initiated a province-wide CRC screening initiative called the ColonCancerCheck program [2]. This program targeted Ontarians aged 50 - 74 and recommended that they undergo at-home screening using guaiac fecal occult blood testing (gFOBT) biennially. Ontarians that had received a flexible sigmoidoscopy (FS) in the last 5 years or a colonoscopy in the last 10 years were considered to be upto-date with CRC screening [2] [3]. This program resulted in a significant rise in CRC screening: from 37.9\% among screening-eligible adults in 2005 to 53\% in 2010. Despite this increase, Ontario screening rates are still considered low and it appears that CRC screening has plateaued since 2010 [3]. Increasing screening rates are important as it has been reported that even with only $70 \%$ of the eligible population screened, CRC mortality could drop by a corresponding 13\% - 15\% [2].

Several barriers to CRC screening have been reported in the literature, many of which encompass social determinants of health. The most commonly cited factors correlated with under-screening include low level of education, low socioeconomic status (SES), lack of acculturation/recent immigration, lack of insurance, no primary care provider, ethnicity (specifically African-Americans, Hispanics and Asians in the US), and male gender [4][12]. Other factors that are weakly associated with under-screening or are not commonly reported include the presence of co-morbidities (including chronic disease and mental health), age (inconsistent evidence suggests that younger individuals are less likely to be screened), no history of screening for other cancers, lack of exercise, unmarried status, and negative health behaviours (e.g. smoking, obesity, etc.) [2] [7] [13]-[16]. Of all these factors, SES is a particularly important social determinant, accounting for up to $62 \%$ in the variance of CRC screening participation rates [9]. Loco-regional data is also important when identifying barriers to CRC screening, since interventions developed to increase screening rates are more successful if they cater to the needs of a local population [17]. There are no studies to date which have evaluated the potential barriers to CRC screening in Toronto's inner city population.

The primary objective of this study was to describe the specific socio-demographic variables that were associated with CRC under-screening in an urban, inner city population. The secondary objective was to determine the overall proportion of eligible patients who were not appropriately screened.

\section{Methods}

\subsection{Study Design and Setting}

A retrospective chart review of patients eligible for average-risk CRC screening as per Ontario's ColonCancerCheck program guidelines was conducted at an academic inner city family health practice in Toronto. The Department of Family \& Community Medicine, affiliated with St. Michael's Hospital in Toronto, Ontario caters to a large and diverse inner city population of patients, and its providers have expertise in areas of HIV primary care, addiction medicine, and care of poor, homeless or under-housed populations, adolescents and new immigrants.

Patients were eligible for inclusion in the study if they were current patients of the family practice, defined as having had at least 1 visit per year during the study period (January 1, 2011 to December 31, 2012) and at least 1 visit within the year preceding the study period, 50 years or older as of January 1st, 2011, and 74 or younger as of December 31st, 2012. To ensure that only individuals eligible for average-risk screening were assessed, exclusion criteria included: patients with a previous diagnosis of CRC, those with one or more first-degree relatives with CRC, and those with hereditary or familial syndromes which predispose an individual to CRC. Only patients that were eligible for CRC screening as of the start of the study period were considered eligible for inclusion.

Information collected from retrospective chart review included age, gender, marital status, occupation, postal code, immigration status, smoking history, current psychiatric illness, history of cancer screening for breast, 
prostate or cervical cancer, and date of last gFOBT, FS, or colonoscopy.

Socioeconomic status of individuals was assessed using two methods: 1) individuals on disability programs (for example, Ontario Disability Support Program (ODSP)) or that were unemployed were compared to those that were listed as employed or retired, and 2) the postal codes of each patient were used to determine their Quintile of Annual Income Per Person Equivalent (QAIPPE). This method, devised by Statistics Canada, takes a household size-adjusted measure of household income from the 2006 census for a particular postal code and expresses it in person-equivalents implied by the low income cut-offs [18]. Patients were assigned to an income quintile ranging from 1 (lowest income) to 5 (highest income).

\subsection{Statistical Methods and Considerations}

A randomized list of 200 patients that met the inclusion/exclusion criteria was generated. This sample size was selected to balance both the feasibility of time required for data collection yet still providing a reasonable number of patients for analysis. Using the 2009 Statistics Canada report on CRC testing [2], two measures were chosen that were anticipated to be significant in this study: low SES and recent immigration status. Using statistical inference of proportions [19] with a type I error rate of 0.05 and a sample size of 200, the calculated power was 0.82 .

Descriptive statistics were used to describe the study population. Simple measures of association, such as t-tests and chi-square tests, were used to determine the relationships between screening and demographic characteristics. All statistics were generated through SAS (version 9.4, SAS institute, Cary, NC) statistical software.

This study was approved by the St. Michael's Hospital Research Ethics Board.

\section{Results}

Of the 200 randomly selected patients meeting inclusion and exclusion criteria, 54\% were male, and the majority were non-immigrants (77.5\%), non-smokers (70.5\%), had a history of prior cancer screening for other sites (78\%), had no psychiatric illness (77\%) and were employed or retired (76.5\%) (Table 1).

A total of 110 patients (55\%) were up to date with CRC screening according to guidelines. The two most common screening methods were gFOBT and colonoscopy: 60 patients (30\%) had a gFOBT and 62 patients (31\%) had a colonoscopy that fell within screening guidelines. Of the 90 patients that were not up to date on CRC screening, 27 (13.5\%) had been previously screened but were no longer within guidelines. The remaining 63 patients (31.5\%) had no history of any prior CRC screening (Table 2).

Patients with psychiatric illness ( $p=0.0005)$, with no history of prior screening for other cancers $(p=0.0001)$, on disability or unemployed $(p=0.0010)$, or who were younger $(p=0.0062)$ were significantly less likely to undergo CRC screening (Table 3, Figure 1). Current smokers were less likely to undergo CRC screening ( $\mathrm{p}=$ 0.0572). When comparing QAIPPE income quintiles, no significant difference in screening rates were found between all quintiles $(\mathrm{p}=0.9965)$ (Figure 2).

\section{Discussion}

The CRC screening rate within our academic, inner city family practice compares favourably to the rest of Ontario. Our study found that 55\% of patients sampled were up-to-date with CRC screening compared with $53 \%$ of Ontarians and 51\% specifically where St. Michael's Hospital is located in the Toronto Central Local Health Integrated Network (LHIN) [3]. In 2010, the Toronto Central LHIN had one of the lowest percentages of up-to-date gFOBT (23\% versus $27 \%$ across Ontario) [3]. We found that $29.5 \%$ of our patients had an up to date gFOBT. This slight increase in screening among our study participants may be a reflection of a general increase in screening in 2012, improved recruitment within our practice due to the academic nature of the site, or a lack of primary care providers for individuals in the Toronto Central LHIN. It has been shown that encouragement from primary health care providers is a powerful persuader for patients to follow through with CRC screening [3].

The four demographic variables found to be significantly related to poorer CRC screening were younger age, no prior history of other cancer screening, active psychiatric illness, and being on disability or unemployed. Similar results have been reported with patients 65 years and under significantly less likely to undergo CRC screening [2] [3]. The association between no prior history of other cancer screening and low CRC screening has 
Table 1. Patient demographics.

\begin{tabular}{|c|c|}
\hline \multicolumn{2}{|c|}{ Age } \\
\hline Mean $=61$ & Range: 50 - 75 \\
\hline \multicolumn{2}{|c|}{ Gender } \\
\hline$M=108(54 \%)$ & $F=92(46 \%)$ \\
\hline \multicolumn{2}{|c|}{ Relationship status } \\
\hline Married/Common Law & 103 (51.5\%) \\
\hline Single & 49 (24.5\%) \\
\hline Divorced/Separated & 35 (17.5\%) \\
\hline Widowed & $12(6 \%)$ \\
\hline Unknown & $1(0.5 \%)$ \\
\hline \multicolumn{2}{|c|}{ Immigration status } \\
\hline Non-immigrant & $155(77.5 \%)$ \\
\hline $20+$ years & $16(8 \%)$ \\
\hline 10 - 19 years & $11(5.5 \%)$ \\
\hline $0-9$ years & $4(2 \%)$ \\
\hline Unknown & $14(7 \%)$ \\
\hline \multicolumn{2}{|c|}{ Current smoker? } \\
\hline Yes & $54(27 \%)$ \\
\hline No & $141(70.5 \%)$ \\
\hline Unknown & $5(2.5 \%)$ \\
\hline \multicolumn{2}{|c|}{ History of other cancer screening } \\
\hline Yes & $156(78 \%)$ \\
\hline No & $78(39 \%)$ \\
\hline Unknown & $5(2.5 \%)$ \\
\hline \multicolumn{2}{|c|}{ Psychiatric illness? } \\
\hline Yes & $46(23 \%)$ \\
\hline No & $154(77 \%)$ \\
\hline \multicolumn{2}{|c|}{ On disability or receiving unemployment } \\
\hline Yes & 47 (23.5\%) \\
\hline No & $153(76.5 \%)$ \\
\hline \multicolumn{2}{|c|}{ Neighbourhood income quintiles by postal code } \\
\hline 1 (lowest) & 49 (24.5\%) \\
\hline 2 & 39 (19.5\%) \\
\hline 3 & $26(13 \%)$ \\
\hline 4 & $34(17 \%)$ \\
\hline 5 (highest) & $46(23 \%)$ \\
\hline Unknown & $6(3 \%)$ \\
\hline
\end{tabular}

\section{Table 2. Comparison of screening modalities used and CRC screening status.}

\begin{tabular}{cccc}
\hline Screening modality & Up to date CRC screening & Out of date CRC Screening & Total \\
\hline gFOBT only & 48 & 23 & 71 \\
Colonoscopy only & 50 & 2 & 52 \\
gFOBT + colonoscopy & 12 & 2 & 14 \\
No testing performed & 0 & 63 & 63 \\
Total & 110 & 90 & 200 \\
\hline
\end{tabular}


Table 3. Association between demographic characterisitcs and CRC screening.

\begin{tabular}{|c|c|c|c|}
\hline Characteristic & CRC screening up to date $(\mathrm{n}=110)$ & CRC screening not up to date $(\mathrm{n}=90)$ & p-value \\
\hline Age group & n (\%) & & 0.0062 \\
\hline $50-59$ & $46(41.8)$ & $52(57.8)$ & \\
\hline $60-69$ & $40(36.4)$ & $32(35.6)$ & \\
\hline $70-74$ & $24(21.8)$ & $6(6.7)$ & \\
\hline Gender & & & 0.4937 \\
\hline Male & $57(51.8)$ & $51(56.7)$ & \\
\hline Female & $53(48.2)$ & $39(43.3)$ & \\
\hline Relationship status & & & 0.3071 \\
\hline Single, widowed, divorced/separated & $49(45.0)$ & $47(52.2)$ & \\
\hline Married/common law, long-term partner & $60(55.0)$ & $43(47.8)$ & \\
\hline Immigration status & & & 0.3551 \\
\hline Non-immigrant & 89 (85.6) & $66(80.5)$ & \\
\hline Immigrant & $15(14.4)$ & $16(19.5)$ & \\
\hline Current smoker & & & 0.0572 \\
\hline Yes & $24(22.2)$ & $30(34.5)$ & \\
\hline No & $84(76.4)$ & $57(63.3)$ & \\
\hline History of other cancer screening & & & 0.0001 \\
\hline Yes & 97 (89.8) & $59(67.8)$ & \\
\hline No & $11(10.0)$ & $28(31.1)$ & \\
\hline Psychiatric illness & & & 0.0005 \\
\hline Yes & 15 (13.6) & $31(34.4)$ & \\
\hline No & $95(86.4)$ & $59(65.6)$ & \\
\hline On disability/receiving unemployment & & & 0.0010 \\
\hline Yes & $16(14.6)$ & $31(34.4)$ & \\
\hline No & $94(85.4)$ & $59(65.6)$ & \\
\hline Income quintile & & & 0.9965 \\
\hline 1 & $28(25.9)$ & $21(24.4)$ & \\
\hline 2 & $21(19.4)$ & $18(20.9)$ & \\
\hline 3 & 15 (13.9) & $11(12.8)$ & \\
\hline 4 & $19(17.6)$ & $15(17.4)$ & \\
\hline 5 & 25 (23.2) & $21(24.4)$ & \\
\hline
\end{tabular}

been reported in prior literature [7] [15]. One study reported that individuals who attributed embarrassment and discomfort to breast or prostate cancer screening were significantly less likely to undergo CRC screening [11]. Patient perception therefore maybe an important contributor as to why some individuals choose not to participate in any form of cancer screening. Interestingly, individuals reporting "single” as their relationship status and new immigrants (less than 20 years in Canada) have been shown to be significantly less likely to undergo CRC screening [2]. These results were not reproduced within our study, which may reflect the inner city medicine expertise and familiarity our providers have in working with new immigrant populations, or perhaps that once new immigrants and "single” individuals find primary care providers they are no longer at a disadvantage with respect to CRC screening.

As stated previously, low SES is a particularly important contributor to poor CRC screening rates [2] [4]-[12]. Individuals in the two lowest income quintiles ( 1 and 2 ) have been reported to be significantly less likely to be screened for CRC when compared to the national average [2]. While our study found no significant differences between the individual income quintiles, we did find a significant difference in CRC screening rates between in- 


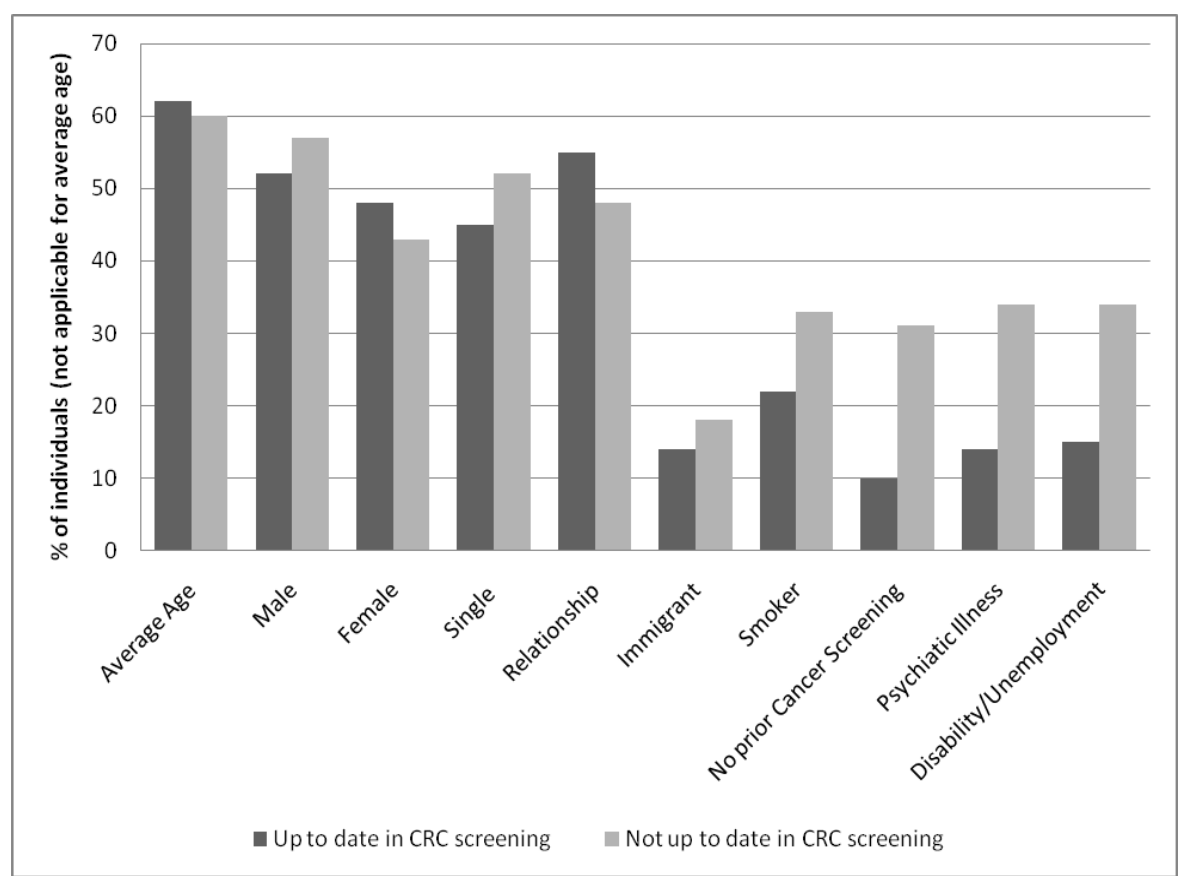

Figure 1. Comparison of demographics and CRC screening status.

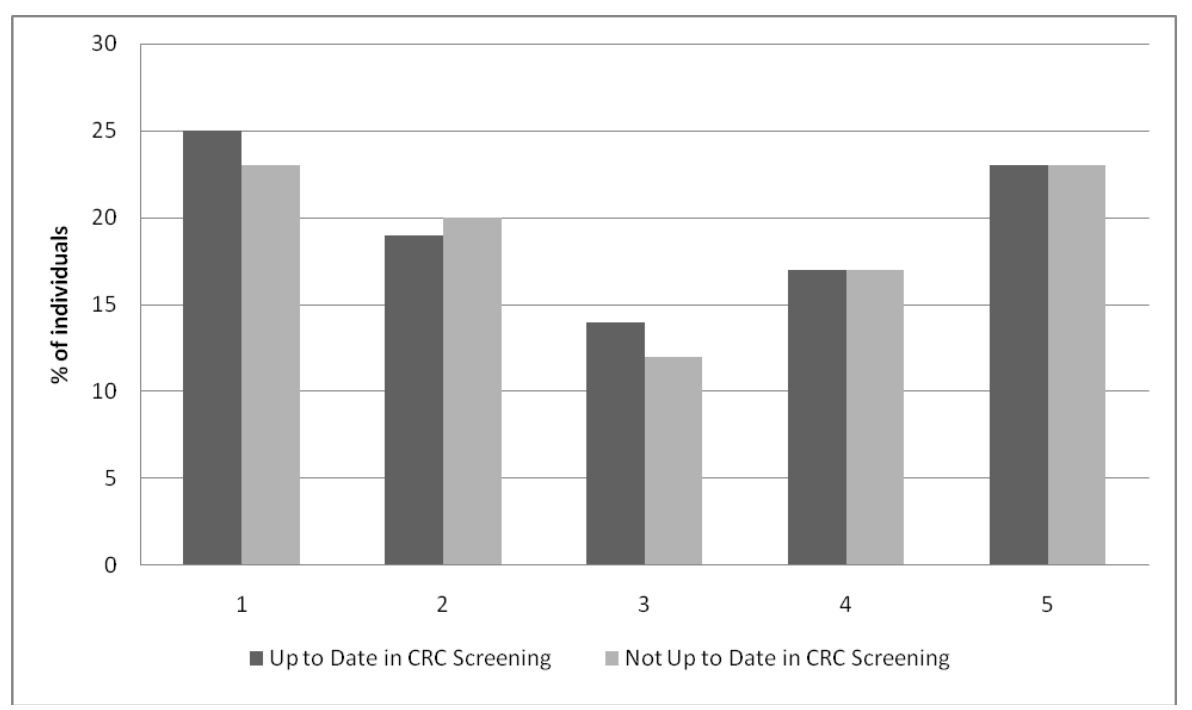

Figure 2. Comparison of income quintiles and CRC screening status.

dividuals on disability or unemployment. Toronto neighbourhoods have drastically changed over the last 10 to 20 years with the gentrification of the city's core and the start of mixed-income revitalization projects in traditionally poorer neighbourhoods [20]. QAIPPE income data, which relies heavily on average household income within a postal code, may be skewed to under represent low-income earners and may be a key reason why income quintiles were not found to be significant in this study.

A highly significant finding in this study was the association between lack of CRC screening and mental illness. Several other studies have reported lower cancer screening rates in patients with mental illnesses but few have addressed the reasons for such a discrepancy. Factors such as poor communication and lack of continuity of care between primary care providers and psychiatric services, stigma of mental illness, time and resource constraints, health and lifestyle factors of patients and effects of mental illness have all been reported as potential reasons for poor cancer screening [21] [22]. As patients with serious mental illnesses are approximately 2.6 
times more likely to develop cancer and 3.5 times more likely to develop colorectal cancer than the general population [23], this is an important area of future research that warrants exploration.

Several strategies have been proposed by CCO to increase CRC screening rates. Proposed plans include expanding their invitation system to reach more newly-eligible Ontarians and more individuals requiring re-screening, increasing support of public and provider education, and potentially implementing fecal immunochemical tests (FIT) to replace the gFOBT. The newer FITs are more sensitive and associated with higher screening participation as they require less at home stool sampling [2].

There are a few limitations to this study. As this is a retrospective review, the data collected is subject to selection bias as well as physician reporting and recall. In addition, a randomly selected sample of 200 individual charts was used to extrapolate findings for all patients and therefore these findings may not be completely generalizable. Finally, this is a single institution study and may not be completely representative of Toronto's inner city population as all the individuals studied had primary health care providers.

\section{Conclusion}

Colorectal cancer screening rates at this academic, inner city family practice are analogous to province wide screening data. Barriers to CRC screening included being younger, having a psychiatric illness, being on disability or unemployed, and having no prior history of any cancer screening. Smoking was of borderline significance. Future studies that focus on group specific interventions to increase CRC screening uptake are warranted.

\section{References}

[1] Canadian Cancer Society’s Steering Committee on Cancer Statistics (2013) Canadian Cancer Statistics. Canadian Cancer Society, Toronto.

[2] Wilkins, K. and Shields, M. (2009) Colorectal Cancer Testing in Canada-2008. Health Reports, 20, 21-30.

[3] Cancer Care Ontario (2012) ColonCancerCheck 2010 Program Report. Cancer Care Ontario, Toronto.

[4] Benarroch-Gampel, J., Sheffield, K.M., Lin, Y.L., Kuo, Y.F., Goodwin, J.S. and Riall, T.S. (2012) Colonoscopist and Primary Care Physician Supply and Disparities in Colorectal Cancer Screening. Health Services Research, 47, 11371157. http://dx.doi.org/10.1111/j.1475-6773.2011.01355.X

[5] Dimitrakaki, C., Boulamatsis, D., Mariolis, A., Kontodimopoulos, N., Niakas, D. and Tountas, Y. (2009) Use of Cancer Screening Services in Greece and Associated Social Factors: Results from the Nation-Wide Hellas Health I Survey. European Journal of Cancer Prevention, 18, 248-257. http://dx.doi.org/10.1097/CEJ.0b013e32832405d6

[6] Klabunde, C.N., Cronin, K.A., Breen, N., Waldron, W.R., Ambs, A.H. and Nadel, M.R. (2011) Trends in Colorectal Cancer Test Use among Vulnerable Populations in the United States. Cancer Epidemiology, Biomarkers \& Prevention, 20, 1611-1621. http://dx.doi.org/10.1158/1055-9965.EPI-11-0220

[7] Red, S.N., Kassan, E.C., Williams, R.M., Penek, S., Lynch, J., Ahaghotu, C. and Taylor, K.L. (2010) Underuse of Colorectal Cancer Screening among Men Screened for Prostate Cancer: A Teachable Moment? Cancer, 116, 4703-4710. http://dx.doi.org/10.1002/cncr.25229

[8] von Wagner, C., Baio, G., Raine, R., Snowball, J., Morris, S., Atkin, W., Obichere, A., Handley, G., Logan, R.F., Rainbow, S., et al. (2011) Inequalities in Participation in an Organized National Colorectal Cancer Screening Programme: Results from the First 2.6 Million Invitations in England. International Journal of Epidemiology, 40, 712-718. http://dx.doi.org/10.1093/ije/dyr008

[9] von Wagner, C., Good, A., Wright, D., Rachet, B., Obichere, A., Bloom, S. and Wardle, J. (2009) Inequalities in Colorectal Cancer Screening Participation in the First Round of the National Screening Programme in England. British Journal of Cancer, 3, S60-S63. http://dx.doi.org/10.1038/sj.bjc.6605392

[10] White, A., Vernon, S.W., Franzini, L. and Du, X.L. (2011) Racial and Ethnic Disparities in Colorectal Cancer Screening Persisted despite Expansion of Medicare’s Screening Reimbursement. Cancer Epidemiology, Biomarkers \& Prevention, 20, 811-817. http://dx.doi.org/10.1158/1055-9965.EPI-09-0963

[11] Paddison, J.S. and Yip, M.J. (2010) Exploratory Study Examining Barriers to Participation in Colorectal Cancer Screening. The Australian Journal of Rural Health, 18, 11-15. http://dx.doi.org/10.1111/j.1440-1584.2009.01114.X

[12] Le Retraite, L., Eisinger, F., Loundou, A., Rinaldi, Y., Seitz, J.F. and Auquier, P. (2010) Sociogeographical Factors Associated with Participation in Colorectal Cancer Screening. Gastroenterological Clinical Biology, 34, 534-540. http://dx.doi.org/10.1016/j.gcb.2010.06.007

[13] Kodl, M.M., Powell, A.A., Noorbaloochi, S., Grill, J.P., Bangerter, A.K. and Partin, M.R. (2010) Mental Health, Frequency of Healthcare Visits, and Colorectal Cancer Screening. Medical Care, 48, 934-939. 
http://dx.doi.org/10.1097/MLR.0b013e3181e57901

[14] Keating, N.L., O’Malley, A.J., Murabito, J.M., Smith, K.P. and Christakis, N.A. (2011) Minimal Social Network Effects Evident in Cancer Screening Behavior. Cancer, 117, 3045-3052. http://dx.doi.org/10.1002/cncr.25849

[15] Sinicrope, P.S., Goode, E.L., Limburg, P.J., Vernon, S.W., Wick, J.B., Patten, C.A., Decker, P.A., Hanson, A.C., Smith, C.M., Beebe, T.J., et al. (2012) A Population-Based Study of Prevalence and Adherence Trends in Average Risk Colorectal Cancer Screening, 1997 to 2008. Cancer Epidemiology, Biomarkers \& Prevention, 21, 347-350. http://dx.doi.org/10.1158/1055-9965.EPI-11-0818

[16] Walter, L.C., Lindquist, K., Nugent, S., Schult, T., Lee, S.J., Casadei, M.A. and Partin, M.R. (2009) Impact of Age and Comorbidity on Colorectal Cancer Screening among Older Veterans. Annals of Internal Medicine, 150, 465-473. http://dx.doi.org/10.7326/0003-4819-150-7-200904070-00006

[17] Holden, D.J., Harris, R., Porterfield, D.S., Jonas, D.E., Morgan, L.C., Reuland, D., Gilchrist, M., Viswanathan, M., Lohr, K.N. and Lyda-McDonald, B. (2010) Enhancing the Use and Quality of Colorectal Cancer Screening. Evidence Report/ Technology Assessment, 190, 1-195.

[18] Wilkins, R. (2010) PCCF+ Version 5F User’s Guide. Health Statistics Division, Statistics Canada, Ottawa, Ontario.

[19] Rosner, B. (2011) Chapter 7: Hypothesis Testing: Categorical Data/Estimation of Sample Size and Power for Comparing Two Binomial Proportions. Fundamentals of Biostatistics, 7th Edition, Brooks/Cole, Boston.

[20] Caulfield, J. (1994) Chapter 3: Reform, Deindustrialization, and the Redirection of City-Building. City Form and Everyday Life: Toronto's Gentrification and Critical Social Practice, University of Toronto Press, Toronto, 65.

[21] Howard, L., Barley, E., Davies, E., Rigg, A., Lempp, H., Rose, D., Taylor, D. and Thornicroft, G. (2010) Cancer Diagnosis in People with Severe Mental Illness: Practical and Ethical Issues. The Lancet Oncology, 11, 797-804. http://dx.doi.org/10.1016/S1470-2045(10)70085-1

[22] Lawrence, D. and Kisely, S. (2010) Inequalities in Healthcare Provision for People with Severe Mental Illness. Journal of Psychopharmacology, 24, 61-68.

[23] McGinty, E., Zhang, Y., Guallar, E., Ford, D., Steinwachs, D., Dixon, L., Keating, N. and Daumit, G. (2012) Cancer Incidence in a Sample of Maryland Residence with Serious Mental Illness. Psychiatric Services, 63, 714-717. http://dx.doi.org/10.1176/appi.ps.201100169 